\title{
1. Living the dream ... but for how long? Being an early-career academic in the context of 'excellence'
}

\author{
Marilena Antoniadou
}

\section{EARLY-CAREER ACADEMICS}

This chapter defines early-career academics (ECAs) as those who have completed their PhD within the last five years (Laudel and Gläser, 2008); yet as explained in other chapters of this book, this definition has been strained due to the diversifying of pathways into academia. Whilst the $\mathrm{PhD}$ provides grounding in research, it does not seem to prepare ECAs to design and deliver high quality teaching, design curricula, use educational technologies, and engage with the broader community or develop leadership capacity. Higher education (HE) research demonstrated that ECAs feel insufficiently prepared for these extra responsibilities in the modern turbulent context (Matthews et al., 2014).

For ECAs who pursue academic careers in the first five years following $\mathrm{PhD}$ completion, becoming a part of the academic culture involves a process of transition and adjustment (Bosanquet et al., 2016; Price et al., 2015). However, the transitory periods of entering the academic profession may appear similar to those of relocating to a new country's university, which demonstrates, more broadly, the intensity and complexity of human experience as people cross multiple borders. For example, based on an ethnographic study, Barkhuizen (2002) characterised the transition of a British academic, who accepted his first academic position in a South African university as an iterative process of overlapping phases: conforming, coping, generating, opposing, and resisting (by actively participating in attempts to change the system). However, one of the study's limitations was that these categories might resonate more with young, early-career academics who are also migrant academics, highlighting the similarities that these two groups may have. 
On entering academia, newcomers take the initiative in figuring out the everyday practices of the academic world, as well as discovering what this world looks like and how it functions (Nixon, 1996). Unlike migrant academics, who mainly struggle with socio-cultural adaptation, the issues encountered by ECAs include time pressures to prioritise research over teaching, struggles with work-life balance, and worries about keeping a job and passing probation (Bosanquet et al., 2016). For ECAs, teaching and interacting with students are overwhelmingly the primary roles that define their academic identity, while for more established academics, developing their scholarly role and their own academic specialism is a much greater concern (Gale, 2011).

Despite the commitment of ECAs and their enthusiasm for teaching, the first stages of an academic career can be very individualistic and isolated (Churchman and King, 2009). Particularly in the UK, becoming an academic at a young age (under 35) is neither smooth nor straightforward, but involves perceptions of inauthenticity, marginalisation and exclusion, amplified through central characteristics of the academics' identities, such as race/ethnicity, social class, and gender (Archer, 2008). Younger, newly appointed academics from minority ethnic and workingclass backgrounds undergo dissonant socialisation experiences and find it difficult to inhabit the identity of an authentic and successful academic (Archer, 2008; Smith, 2010). Similarly, while stereotypes frame international academics in terms of their cultural background (Mizzi, 2013), ECAs are often presumed to be naïve and inexperienced by the larger community of academics (Teferra, 2016).

The ECAs' persistent attempts to succeed are also challenged by their realisation and shock about the highly individualistic and competitive culture of academia (Gravett and Petersen, 2007; Smith, 2010; Price et al., 2015). British universities have been characterised by 'a cult of amateurism', with new members of staff receiving little or no formal training in the basics of academic work, with the more experienced academics learning by doing the job (Blaxter et al., 1998: 282). These views are echoed in other studies (Boice, 1992; Lucas and Murry, 2016; Nixon, 1996) which found that newcomers expected interaction and assistance from others, especially with regard to scholarship and teaching, but were disappointed by the lack thereof. New academic staff reported experiences of tension and identity conflict with evidence of them attempting to resist the competing pressures of contemporary academia (Archer, 2008; Fitzmaurice, 2013; Green and Myatt, 2011). Carrying heavy teaching workloads in the first years of their academic career prevented them from allocating space for research to develop their scholarly profile (Fitzmaurice, 2013). Subsequently, as they learned to 
negotiate competing demands around lecturing, meetings, course coordination and research, the first period in academia was characterised by despair, isolation, loneliness, lack of intellectual stimulation, and even questioning their choice of career, their suitability for academia, and their ability to develop as scholars (Boice, 1992; Gravett and Petersen, 2007). Specifically, job insecurity heightened the pressure for ECAs to win grants and fellowships in order to become competitive for future promotions, which unavoidably left them with thoughts of leaving academia (Bosanquet et al., 2016). Importantly, being mentored by senior counterparts was identified as an important tool in helping new academics with their adjustment to academic expectation (Teferra, 2016; Solem and Foote, 2004), although this adjustment is more difficult for foreign-born staff, who also have to adjust to different educational systems and social culture (Moody, 2004).

\section{ECAS IN THE CONTEXT OF 'EXCELLENCE'}

The literature identifies ECAs as a vulnerable academic group based on its limited capacity to resist the growing neoliberalism of higher education and to deal with its associated problems (Bristow et al., 2017; Laudel and Gläser, 2008). Other studies present ECAs as a group which actively seeks its identity construction whilst coping with challenges, anxiety, and disillusionment (Smith, 2010; Trowler and Knight, 2000). In addition, ECAs are presented with opportunities to make a significant difference in their working lives (e.g. Archer, 2008; Harris, 2005; Smith, 2010). This study's interest was to capture the ECAs' experiences in entering the profession, with the idea of being an 'excellent' academic (Butler and Spoelstra, 2012) in the UK 'new higher education' (Jary and Parker, 1998) as the empirical context.

Higher education is experiencing a period of profound change; the neoliberal audit culture in academia and its clash with the older values of academic freedom and vocation is a global phenomenon. In the UK, it has become further strengthened by sustained state intervention in $\mathrm{HE}$ governance. Government initiatives, such as the introduction of tuition fees, the replacement of equity-based with competition-based university funding now distributed through the nation-wide Research Excellence Framework $(\mathrm{REF}),{ }^{1}$ and the Teaching Excellence Framework $(\mathrm{TEF})^{2}$

1 REF is the acronym of the Research Excellence Framework on which UK Higher Education research funding is based.

2 The Teaching Excellence Framework 'is designed to recognise, reward and improve teaching excellence' in the UK. 
have generated a quasi-market environment maintained by a punishing regime of academic performance management. This is underpinned by extensive use of league tables and journal rankings that exert considerable pressure on academic agendas and identities (Butler and Spoelstra, 2012; Willmott, 2003). Academics are now expected to be 'successful' and defined by 'academic excellence' (Butler and Spoelstra, 2012), contingent on continuing achievement of the latest and often highly demanding targets.

The implications of these forces on $\mathrm{HE}$ are particularly evident in relation to ECAs (Bristow et al., 2017). Financial pressures mean that sessional staff (rather than more expensive permanent lecturers), are carrying out much of the teaching work (Bexley et al., 2011). Opportunities for ECAs are therefore declining in relative terms as more $\mathrm{PhD}$ qualified people enter the job market and compete for positions. According to the Universities UK $(2007,2015)$ reports, there are not enough young UK academics coming into the academic profession, whilst there are growing numbers of older academics (66 and over) currently continuing in the profession. The academic workforce is ageing worldwide (OECD, 2008) due to unsatisfactory remuneration and unfavourable working conditions that have reduced the attractiveness of academic careers in many countries, including the UK. Considering the relatively low turnover of UK-born ECAs, there is little in the literature about the experiences of how UK-based ECAs respond to the apparent difficulties of the profession.

Few systematic efforts (e.g. Bristow et al., 2017) have been made to explore the different roles, experiences and practices of academics in their early career stages and little has been done to show the resilience and resistance of these academics, who constitute both the present and the future of the academic profession. This chapter, therefore, examines the predicament in which ECAs find themselves in the current $\mathrm{HE}$ context, as gleaned through their own understandings of themselves as participants in the complex and contradictory forces constituting their field. The following sections discuss findings from a study of ECA experiences in the UK, with a view to contributing to the broader conversation. In particular, the study explored narratives of their efforts in relation to the pressures of an increasingly market-driven, neoliberal institutional context, yet arguing that being an ECA also involves resistance and compliance as an integral part of the role. 


\section{METHODS}

In addressing the study's goals, 17 semi-structured interviews were conducted with ECAs working in business schools across the UK. The UK was chosen because, as explained earlier, the rapid changes in UK universities in the past decades have turned them into sites of a particularly insidious enactment of neoliberalism within academia where the state and market come together in a specific manner (Deem and Brehony, 2005; Bristow et al., 2017; Butler and Spoelstra, 2012; Willmott, 2003), thus making the UK a suitable context for this exploratory study.

In selecting participants, ECAs chosen were those employed in a full-time academic post for up to five years (Laudel and Gläser, 2008). The first few interviewees were approached through personal networks and then acted as 'seeds' for the subsequent waves of participant recruitment (Heckathorn, 2011). Throughout the snowball recruitment, the aim was to ensure diversity of ECAs' demographics and experiences. The final sample consisted of 17 ECAs varying in age (from 28 to 34), gender, discipline and university background, and at different career stages from one to five years, across the UK.

The interviews used a set of pre-prepared questions as a guide to prompt the interviewees' stories and ensure that research aims were addressed. This semi-structured guide included questions about being an ECA within a UK neoliberal context, and critical events in which they saw themselves coping and attempting to make a difference in their institutions. To achieve this and gather particular instances and examples, the critical incident technique was used (Flanagan, 1954). These incidents included events such as decisions and realisations, alongside significant events, such as confrontations and conflicts. Interviews took place at participants' offices and ranged in length from one to one-anda-half hours. Thematic analysis of the transcripts was carried out in several stages. As a result, three interconnected themes emerged, as discussed below. Each of these themes is presented separately, but there is considerable overlap between them. Reference is made to the relevant literature where appropriate.

\section{FINDINGS}

\section{'Living the Dream'}

This first theme underlies the reasons why the participants pursued an academic career. The participants referred to their own hopes and 
aspirations and the values and beliefs underpinning professional work. Once they entered the profession, they claimed to have one of their dreams come true, or as one participant said, 'I was living the dream', and were keen to commence their job with enthusiasm and passion. The majority were looking forward to teaching, to having their own students, and to researching and publishing, as this was central to their identity. As a female participant with one year of experience said:

For me this was a dream job. That's why I did the PhD. It's about having a natural passion for education and knowledge and attitude to educate students, that is very important to me. And it's not something you do 9 till 5. The research element does play a significant role in my idea of an academic's life, but above all I was more intrigued by the teaching part of it.

Another female participant said how she felt when she first secured her job:

I fought and took the job offer because I had always wanted to work in HE. There is a mystique on the job, the sophistication, the intellectualism. I had this image in my mind of what an academic is like.

Teaching is important to the ECAs as a way of being in the world (Fitzmaurice, 2013). From the participants' accounts, working in academia is a very personal decision, based on an image of being an intellectual being (Du Plessis et al., 2013). For many participants being asked to design and deliver extra responsibilities was perceived as 'an honour', without yet realising the hectic demands of the job. As a male participant with two years of experience said:

Entry into an academic career is an arduous process. But it's a lifetime experience to say 'I'm a lecturer', so I was proud. My manager asked me to do extra bits and pieces in my first year and I was taking the responsibility with joy. I thought 'wow I'm useful'. I ended up working seven days a week, but I didn't mind because I thought 'I must be doing something right to be busy'.

The participants referred to the high status and prestige the job gives, and despite any difficulties they encountered they were flattered by their new job role. This is what Laudel and Gläser (2008) called a 'status passage' where ECAs move from the periphery to the core profession and high-status academia, which characterises the first period of being an ECA. For the participants of this study, the experience of research and teaching is what defined academic life, and they showed motivation to develop and support their discipline in terms of both research and 
teaching, something that was found in other studies as a feature of being an ECA (e.g. Filene, 2005).

\section{'Tensions and Contradictions'}

Soon after their recruitment, the participants had to change their existing perceptions and expectations about what it means to be an ECA. The most challenging issue was finding the time for research and managing the demands of modern HE. Participants mentioned that the tasks associated with being an academic were very different to what they had envisaged they would be. They claimed that they had to learn to negotiate competing demands around research and teaching, continuous meetings, module design, and administration. This was evidenced from two extracts:

I now find that I am an admin person, not an academic, not a teacher and not a researcher - the stuff I thought I would do!

Abbreviations. Students. Forms. So many of them. I expected to mentally stimulate other people, read, and engage in deep conversations with my colleagues. Instead, I find myself running around trying to find out what I am supposed to do. Never in my life have I sent so many emails and filled in so many forms.

Similar to previous studies (e.g. Gravett and Petersen, 2007; Smith, 2010) ECAs expected the academic community to be characterised by dialogue, collaboration and interaction. However, the participants soon realised that academia can be highly hierarchical and individualistic and that collaboration is not a commonly entrenched practice. Many interviewees gave examples of situations where they were able to make use of their newness to raise objections and do things others would not judge expedient, something that Lave and Wenger (1991: 29) characterised as 'legitimate peripheral participation' to describe the learning process by which newcomers increasingly become part of the social world of a community of practice.

The realisation of being an ECA in the neoliberal era brought, on reflection, disappointment and even desperation. The pressures of "excellence' were evident in this extract:

I'm teaching because I want to contribute and have an impact to the new generation. I want to give them something. Just like what my professors did to me. And I'm doing research because I want to create something and bring change to the field. But after three years in the job, I realised we are doing 
teaching to bring money to the university, and we are doing research because of the REF. My dream of what this job would mean died.

Based on the literature, this disappointment would link to the notion of 'being a stickler' identified by Bristow et al. (2017), involving what the ECAs understand as the various forces and pressures that affect them. The 'stickler' realises that the very core of their values is deeply at odds with the pressures that impact upon them. Indeed, some other participants were dismayed and confused at what they had to face as newcomers:

My experience is very different from what I expected. Now everybody seems to be so busy. I feel like I'm annoying them when I ask for help, despite everyone saying in their emails 'don't hesitate to get in touch'. They expect me to know everything. It's a managerialist, centralised sector. I had to find my way, actually struggle to find my way. You don't know what you need to know. People are competitive, people are obsessed with NSS and REF, they expect me within two years to bring outstanding teaching results and produce REF-able publications. I started thinking that if I don't I won't be respected.

From the day I joined my new job, senior management gave me two years to produce a four-star paper to submit to REF and prepare another three-star or four-star. I thought 'okay great, I've got this'. I'm heading now towards the end of the second year and I feel doomed. It's impossible. I would need to stop teaching, stop sleeping to get two papers out in 23 months. I've got my mentor but it is just not enough.

My dream of what it means to be an academic was shattered after 12 months. Students took over my life. I tried to be helpful and support them saying, 'yeah email whenever' or 'come and see me for a chat'. I wish someone had warned me that in today's education you just DON'T DO THIS. You set barriers. They emailed me during weekends, they queued outside my door, they complained about their grades, then they started complaining about other colleagues. I found myself in deep water and if I hadn't learn to swim, I would have drowned. I thought of finding another job, in the government maybe, but I think my survival skills and flexibility have given me the resilience to stay alive.

These notions contrasted with the participants' original expectations that senior colleagues would direct them or mentor them into the academic community. Indeed, many conveyed the need for someone to help them negotiate the complexities of the job and make explicit the 'rules of the game'. On some occasions, however, participants referred to successful mentoring relationships with their $\mathrm{PhD}$ supervisors, or with their assigned institutional mentors; yet these mentors were sporadically mentioned and did not form the majority of the accounts. 
Learning to negotiate new rules and regulations forms part of the introduction into academia (Archer, 2008; Green and Myatt, 2011) and mentoring was important in helping them survive the challenges. The main implication hereof is that participants had to be extremely creative in finding a personal and appropriate course of action in order to find a way into the social practices and other activities, which characterise the academic community. Most of the participants believed that they were not clear about what was expected of them and thus felt as though they were operating in a world in which the rules of interaction were concealed. Participants in the study revealed the variety of strategies they resorted to for getting ahead in the academic community. These strategies contributed to the third theme on surviving and thriving.

\section{'Surviving and Thriving is Personal'}

Paradoxically, despite the challenges our participants recognised some elements of flexibility in the profession. They commented that although it was up to them to discover the 'rules of the game', they felt they had the power to direct their careers in the way they felt was right for them. As one said:

After having my first annual review, I was asked which route I wanted to go: teaching or research. It was the first time I felt that I have power over my future career in a long time. I knew people could do both, but now I knew that I could sacrifice the one over the other and still keep my job!

Despite their disappointment in what they previously thought the profession represented, they were found to be making efforts to resist and survive:

I feel very insecure at the moment. I'm anxious with where the profession is going. It's so profit-oriented and not knowledge or quality-oriented. I remember I was watching my lecturers and thinking 'their life is perfect, I want to be like them'. Now it is up to me what I want to show to my students.

It's a profession with supreme confidence and competence. And it's tough. Really tough. Not everybody can survive and thrive. I know now that this job is not for everyone. I'm not though willing to give up this identity of being an intellectual who survives challenges.

Indeed, arguments from the literature (Kahn et al., 2008) emphasised that each academic has to find their own path towards an academic identity, which accords with the above extracts. Academics are characterised by 'thick skin' (Du Plessis et al., 2013) and by intense resistance and 'free 
spirit' (Bristow et al., 2017). Our findings suggest that the identity of a new academic is multifaceted and involves individual trajectories based on personality and experience (Gravett and Petersen, 2007; Jawitz, 2009).

\section{CONCLUSION}

The three themes contribute to the existing literature by enhancing knowledge and increasing awareness of the nuanced nature of the experience of becoming a new academic in the modern UK HE sector. This research showed how newcomers describe their experiences of entering academia as a daunting and challenging process. Most of the newcomers entered academia expecting openness, collegiality, connectedness and co-operation. Contrary to their expectations, the modern HE sector is competitive, lacking collegiality and heavily profit-oriented, in alignment with previous studies (Archer, 2008; Fitzmaurice 2013; Green and Myatt, 2011; Lucas and Murray, 2016). Yet, as resistant, 'thick skin', competent individuals, they have chosen not to give up their initial hopes and continue to pursue their dream.

This study further helps to distinguish how experiences of ECAs are different from international academics, who migrate to the UK (Antoniadou and Quinlan, 2018). The interviews with early-career native-born academics have shown somewhat different experiences from their international counterparts (Table 1.1). The international academics' personal, professional and pedagogical concerns, as depicted in previous work (Antoniadou and Quinlan, 2018) overlap with but also differ from ECAs, especially on the issues of socio-cultural, linguistic integration and legal and moving obstacles. Evidently, whilst ECAs mostly struggle with the academic adaptation, international academics need to adapt to academic, socio-cultural and linguistic identity and relationship aspects at the same time. International academics perceived disparities in treatment by colleagues and faced additional anxieties related to differences of accent, cultural values, educational expectations, and housing. Unlike international academics who experienced thoughts of leaving academia, this study's findings revealed (temporary) thoughts about leaving the profession (Bosanquet et al., 2016). Yet, in both groups, their flexibility, self-determination to succeed in a new (or foreign) workplace helped them to introduce ways of practice in HE that helped them move to a thriving mode. 


\section{Table 1.1 Transition and adjustment between international and early-career staff}

International Academics (Antoniadou and Quinlan, 2018)

More experienced and confident in teaching and research, in their home institution.

Perceived barriers of language and UK's culture, lifestyle.

Challenges of integration in UK social and cultural nuances (e.g. the 'night out' and 'drinking culture' in England perceived to be much more lavish).

Generally displayed anxieties about practical challenges (e.g. accommodation, visas) and emotional issues (e.g. homesickness).

No concerns around job security. Smooth adaptation in research and external funding policies.

Pressures resulted in thoughts of leaving the UK.

Stereotyped in terms of cultural background.

Coping is largely based on resilience and the academic's foreignness.

\section{Early-career Academics}

Issues in negotiating competing demands around lecturing, meetings, course coordination and research.

No issues with linguistic adaptation.

No concerns about social and cultural differences.

No concerns about legal status of residency in the UK.

Concerns about job insecurity, lack of confidence to win grants and fellowships, in order to become competitive for future promotions.

Pressures of contemporary academia resulted in thoughts of leaving the profession.

Stereotyped in terms of naivety and inexperience.

Coping is based on mentoring, flexibility and 'thick skin'.

To conclude, this study both emphasises and further elaborates on the role of resistance, determination and compliance in dealing with tensions, contradictions and changes of the current HE neoliberalism. Our participants' understandings of entering and being in academia, offer support to recent arguments (Bristow et al., 2017) that this group of individuals act as resisters and compliers. With a more diverse group of newcomers entering the academic community in the UK and with increasingly regulatory frameworks and policies, it is hoped that more creative means will be found to help ease the path of newcomers into the academic world. 


\section{REFERENCES}

Antoniadou, M. and Quinlan, K.M. (2018). Thriving on challenges: How immigrant academics regulate emotional experiences during acculturation. Studies in Higher Education, 1-15. DOI: 10.1080/03075079.2018.1512567.

Archer, L. (2008). Younger academics' construction of 'authenticity', 'success', and professional identity. Studies in Higher Education, 33(4), 385-403.

Barkhuizen, G. (2002). Beginning to lecture at university: A complex web of socialization patterns. Higher Education Research and Development, 21(1), 93-109.

Bekhradnia, B. and T. Sastry. (2005). Migration of academic staff to and from the UK. Higher Education Policy Institute (HEPI) Report. London: HEPI.

Bexley, E., James, R. and Arkoudis, S. (2011). The Australian academic profession in transition. Canberra: Department of Education, Employment and Workplace Relations, Commonwealth of Australia.

Blaxter, L., Hughes, C. and Tight, M. (1998), Writing in academic careers, Studies in Higher Education, 23(3), 281-295.

Bosanquet, A., Mailey, A., Matthews, K. E. and Lodge, J. M. (2016). Redefining 'early career' in academia: A collective narrative approach. Higher Education Research and Development, 36(5), 1-13.

Boice, R. (1992) The New Faculty Member. Supporting and Fostering Professional Development. San Francisco, CA: Jossey-Bass.

Bristow, A., Robinson, S. and Ratle, O. (2017). Being an early-career CMS academic in the context of insecurity and 'excellence': The dialectics of resistance and compliance. Organization Studies, 38(9), 1185-1207.

Butler, N. and Spoelstra, S. (2012). Your excellency. Organization, 19(6), 891-903.

Churchman, D. and King, S. (2009). Academic practice in transition: Hidden stories of academic identities. Teaching in Higher Education, 14(5), 507-516.

Deem, R. and Brehony, K. J. (2005). Management as ideology: The case of 'new managerialism' in higher education. Oxford Review of Education, 31(2), 217-235.

Du Plessis, G. A., Du Plessis, L. M. and Saccaggi, C. (2013). The lived experiences of professional clinical psychologists who recently started a new academic career. Indo-Pacific Journal of Phenomenology, 13(2), 1-12.

Filene, P. (2005). The Joy of Teaching. Chapel Hill, NC: University of North Carolina Press.

Fitzmaurice, M. (2013). Constructing professional identity as a new academic: a moral endeavour. Studies in Higher Education, 38(4), 613-622.

Flanagan, J.C. (1954). The critical incident technique. Psychological Bulletin, 51(4), 327-358.

Gale, H. (2011). The reluctant academic: Early-career academics in a teachingorientated university. International Journal for Academic Development, 16(3), 215-227.

Gravett, S. and Petersen, N. (2007). 'You just try to find your own way': the experience of newcomers to academia. International Journal of Lifelong Education, 26(2), 193-207. 
Green, W. and Myatt, P. (2011). Telling tales: A narrative research study of the experiences of new international academic staff at an Australian university. International Journal for Academic Development, 16(1), 33-44.

Harris, S. (2005). Rethinking academic identities in neo-liberal times. Teaching in Higher Education, 10(4), 421-433.

Heckathorn, D. D. (2011). Comment: Snowball versus respondent-driven sampling. Sociological Methodology, 41(1), 355-366.

Jary, D. and Parker, M. (1998). Introduction. In D. Jary and M. Parker (Eds.), The new Higher Education: Dilemmas and directions for the post-Dearing university (pp. 3-26). Stoke-on-Trent: Staffordshire University Press.

Jawitz, J. (2009). Academic identities in community of practice in a professional discipline. Teaching in Higher Education, 14(3), 241-251.

Jiang, X., Di Napoli, R., Borg, M., Maunder, R., Fry, H. and Walsh, E. (2010). Becoming and being an academic: the perspectives of Chinese staff in two research-intensive UK universities. Studies in Higher Education, 35(2), $155-170$.

Kahn, P., Young, R., Grace, S., Pilkington, R., Rush, L., Tomkinson, B. and Willis, I. (2008). Theory and legitimacy in professional education: A practitioner review of reflective processes within programmes for new academic staff. International Journal for Academic Development, 13(3), 161-173.

Laudel, G. and Gläser, J. (2008). From apprentice to colleague: The metamorphosis of early career researchers. Higher Education, 55(3), 387-406.

Lave, J. and Wenger, E. (1991). Situated learning: Legitimate peripheral participation. Cambridge: Cambridge University Press.

Lucas, C. and Murry, J.W. (2016). New faculty: A practical guide for academic beginners. New York, NY: Springer.

Matthews, K.E., Lodge, J.M. and Bosanquet, A. (2014). Early career academic perceptions, attitudes and professional development activities: Questioning the teaching and research gap to further academic development. International Journal of Academic Development, 19(2), 112-124.

Mizzi, R. (2013). Crossing borders to teach: A literature review of (dis)location, interconnectedness, and pedagogy. The Canadian Journal for the Study of Adult Education, 25(2), 53-63.

Moody, J. (2004). Faculty Diversity: Problems and Solutions, New York, NY: Routledge.

Nixon, J. (1996). Professional identity and the restructuring of higher education, Studies in Higher Education, 21(1), 5-16.

Organisation for Economic Co-operation and Development. (2008). Tertiary Education for the Knowledge Society - Volume 1: Special features: Governance, Funding, Quality - Volume 2: Special features: Equity, Innovation, Labour Market, Internationalisation. OECD.

Price, E., Coffey, B. and Nethery, A. (2015). An early career academic network: What worked and what didn't. Journal of Further and Higher Education, 39(5), 680-698.

Smith, J. (2010). Forging identities: The experiences of probationary lecturers in the UK. Studies in Higher Education, 35(5), 577-591. 
Solem, M. and Foote, K. (2004). Concerns, attitudes and abilities of early-career geography faculty. Annals of the Association of American Geographers, 94(4), 889-912.

Teferra, D. (2016). Conclusion: The era of mass early career academics and aging faculty - Africa's paradox. Studies in Higher Education, 41(10), 1869-1881.

Thomas, S.L. and Malau-Aduli, B.S. (2013). New international academics' narratives of cross-cultural transition. International Journal of Higher Education, 2(2), 35-52.

Trowler, P. and Knight, P.T. (2000). Coming to know in higher education: Theorising faculty entry to new work contexts. Higher Education Research and Development, 19(1), 27-42.

Willmott, H. (2003). Commercialising higher education in the UK: The state, industry and peer review. Studies in Higher Education, 28(2), 129-141.

Universities UK. (2007). Talent wars: The international market for academic staff. Policy Briefing, July 2007, London (online). Available at: https://dera.ioe. ac.uk/26319/1/TalentWars.pdf (accessed 24 February 2018).

Universities UK. (2015). Patterns and trends in UK Higher Education 2015 (online). Available at: https://www.universitiesuk.ac.uk/policy-and-analysis/ reports/Documents/2015/patterns-and-trends-2015.pdf (accessed 24 February 2018). 